\title{
Koellreutter e Dalcroze: quando o método é não ter método, qual o espaço para os
}

Koellreutter e Dalcroze: when the method is to have not a method, which would be the place for the "active methods"?

Rafael Prim Meurer ${ }^{2}$

Valeria Bittar ${ }^{3}$ 


\section{Resumo}

Este artigo traz reflexões acerca dos distanciamentos ou aproximações entre a proposta de educação musical de HansJoachim Koellreutter, no que se refere essencialmente à sua crítica ao método, $\mathrm{e}$ os chamados "métodos ativos" de educação musical. Aqui, a "análise de discurso" é utilizada como apoio para se compreender o significado do termo "método" para Koellreutter e para Emile JaquesDalcroze, enquanto sujeitos inseridos na história. Para tanto, apresentamos uma breve contextualização histórica sobre a instituição do "método conservatorial" (la méthode), onde propomos um contraponto entre este e as propostas de Koellreutter e os "métodos ativos" (tomando Dalcroze como exemplo). Também propomos a reflexão acerca da utilização do termo "método" como referência à Rítmica Dalcroze. Como desfecho, consideramos que, apesar do caráter de reação ao "método conservatorial" presente nos "métodos ativos", a crítica de Koellreutter também pode se referir a estes, quando compreendidos e "aplicados" de maneira inflexível. Isso não justificaria o desconhecimento dos "métodos ativos" por parte dos professores de música em formação. Pelo contrário, aponta para a necessidade de reflexão acerca dos discursos de educação musical, de modo a

\section{Abstract}

The present article proposes reflections on differences and similarities in the musical education approach as suggested by Hans-Joachim Koellreutter, basically regarding criticism on such method and the so-called "active methods". Discourse Analysis is used as a framework to understand the meaning of the term "method" in Koellreutter's and Emile Jaques-Dalcroze's views while historical subjects. First, a brief historical contextualization of the construction of the "conservatorial method" (la méthode) is presented, therefore, stating a counterpoint among this method, Koellreutter's proposal, and the active methods. To do so, Dalcroze's will be given as an example. Second, there is a discussion on the use of the term "method" when referring to Dalcroze's music education proposal. Finally, there is a consideration that even when reacting to the conservational method observable too in the active methods, Koellreutter's criticism may also refer to them when comprehended and "applied" rigidly. This fact does not justify the lack of knowledge on the "active methods" on the part of music teachers in their formative process. On the contrary, this work emphasizes the need to reflect on the type of musical education discourses used so as to understand the 
melhor conhecer as ideologias existentes neles, tomando consciência de suas possíveis repercussões práticas.

Palavras-Chave:

Koellreutter. Dalcroze. Método. ideologies therein better and, to become more aware of their possible practical repercussions.

Keywords:

Koellreutter. Dalcroze. Method.

ISSN: 1808-3129

\footnotetext{
${ }^{1}$ Este artigo revisa e amplia parte do trabalho de conclusão de curso desenvolvido por Rafael Prim Meurer (2014), intitulado Koellreutter e Dalcroze: reflexões sobre questões do 'método' a partir de uma experiência de estágio, sob a orientação da professora Valeria Bittar, e muitas das reflexões aqui traçadas estão embasadas na tese de doutoramento de Valeria Bittar (2012), intitulada Músico e Ato.

${ }^{2}$ Licenciando em Música pela Universidade do Estado de Santa Catarina (UDESC). atuou como bolsista-docente do PIBID, bolsista de extensão e bolsista de Iniciação Científica. Atuou como cantor/ator em produções cênico-musicais. rafael.p.meurer@gmail.com

${ }^{3}$ Universidade do Estado de Santa Catarina - UDESC anima@animamusica.art.br
} 
Como professores de música em contínua formação, lidamos constantemente com posicionamentos diversos a respeito do modo como a música deve ser abordada em sala de aula, dentro da escola. Dentre as inúmeras ideias de educação musical, há contrastes e convergências em seus direcionamentos. De acordo com Marisa Trench de Oliveira Fonterrada (2005, p. 163-165), durante o século XX, classifica-se os mais influentes educadores musicais como aqueles da "primeira geração" e os da "segunda geração". Os sistemas de educação musical do início do século XX criados pela "primeira geração" são chamados por Fonterrada (2005) de "métodos ativos".

Segundo Fonterrada (2005, p. 107-108), dentre os "métodos ativos" de educação musical, destacam-se: Emile Jaques-Dalcroze, Edgar Willems, Zoltán Kodály, Carl Orff e Shinichi Suzuki. Michelle Mantovani (2009) irá esclarecer adiante que o que seria priorizado na mentalidade da primeira geração seria a vivência, a experiência e o fazer musicais, ao contrário das ideologias contidas nas metodologias oitocentistas que visavam um aprender abstrato:

Por método ativo entende-se uma educação musical pautada na experiência de vida, na vivência prática, que aproxima a música e o educando, diferenciandose, assim, da prática tradicional do ensino de música, em que o contato do aluno com a música se dá por meio da teoria e da técnica, com ênfase na compreensão racional de conceitos, apartada da vivência musical (MANTOVANI, 2009, p. 39).

Na segunda metade do século XX, surgem os educadores musicais da chamada "segunda geração", que se diferenciavam dos anteriores "pela utilização de material musical alinhado às mudanças ocorridas na música de vanguarda, em contraposição à música tradicional e folclórica, enfatizada pelos primeiros" (MANTOVANI, 2009, p. 39). Percebe-se, nestas propostas, grande ênfase nos processos de criação, de composição, de improvisação e de escuta ativa. Fonterrada (2005) compreende como pertencentes a esta segunda geração: George Self, John Paynter, Murray Schafer e Boris Porena.

Hans-Joachim Koellreutter (1915-2005) foi um músico alemão naturalizado brasileiro, representante significativo dos ideais da "segunda geração" no Brasil. Koellreutter ficou conhecido, principalmente através de trabalhos da professora Teca Alencar de Brito (2001; 2015), como o educador musical que propôs, em síntese, a superação do "currículo fechado", o questionamento constante, a centralidade da música enquanto "uma contribuição para o alargamento da consciência e para a modificação do homem e da sociedade" (KOELLREUTTER, 1997, p. 72 apud BRITO, 2001, p. 26) e o ser humano como objetivo da educação musical (BRITO, 2001, p. 42). Em consonância com estes princípios, Koellreutter também afirmava: "Meu método é não ter método. O método fecha, limita, impõe... e é preciso abrir, transcender, transgredir, ir além..."3 (KOELLREUTTER apud BRITO, 2015, p. 18).

Este posicionamento de Koellreutter não aponta para um ou outro método específico, mas para métodos pedagógico-musicais em geral. Considerando as ideias de Koellreutter já expostas acima, pode-se entender que o professor germano-brasileiro se manifesta na direção contrária ao uso indiscriminado e exclusivo de um único

\footnotetext{
${ }^{3}$ Segundo Brito (2015, p. 18), "esta frase foi repetida por Koellreutter em diversas situações, em aulas e conversas informais sobre o assunto".
} 
método de educação musical no meio escolar. O método, sob este ponto de vista, minaria a experiência criativa dos alunos com a música.

É inevitável pensar que possa haver um conflito da proposta koellreuttiana com as propostas de educação musical da "primeira geração" do séc. XX. Os "métodos ativos", de maneira geral, como são conhecidos atualmente, possuem uma sistematização, possuem caminhos metodológicos de maneira teleológica, já definidos a priori, aspecto enfaticamente criticado por Koellreutter. É a partir desse embate que apresentamos algumas reflexões acerca da possível proximidade ou distância entre a proposta de educação musical de Hans-Joachim Koellreutter, no que se refere essencialmente à sua crítica ao "método", e os chamados "métodos ativos de educação musical" (FONTERRADA 2005).

Inicialmente apresentamos uma breve contextualização histórica, já elaborada por outros autores, sobre a maneira como ocorria a formação musical antes dos ideais oitocentistas e como esta foi moldada pela "mentalidade do método conservatorial" (BITTAR, 2012) assinalando um contraponto entre o "método conservatorial" e as propostas de Koellreutter. Mais adiante, apresentaremos o termo "método conservatorial" fazendo referência aos documentos musicais que surgem com a instituição dos conservatórios e que buscam sintetizar um curso completo, demonstrando todos os estágios de uma formação musical específica de modo progressivo, abrangente e claro (SANTOS, 2011).

Utilizando as propostas de Emile Jaques-Dalcroze ${ }^{4}$ como exemplo, apontamos o caráter de crítica ao "método conservatorial" já existente nos princípios defendidos pelos criadores dos "métodos ativos" de educação musical e propomos uma reflexão crítica acerca dos possíveis entendimentos do uso do termo "Método Dalcroze" para se referir à proposta de educação musical de Jaques-Dalcroze por ele denominada de "Rítmica".

Apoiando-me nos princípios da "análise de discurso" (ORLANDI, 2000), percebemos que um estudo sobre os entendimentos possíveis acerca do conceito de método utilizado por Koellreutter é perpassado pela ausência de um estudo mais aprofundado do léxico. Trata-se de uma questão de discurso, uma questão de como as palavras significaram e significam em contextos e experiências históricas diferentes e ditas por sujeitos distintos. Para Eni P. Orlandi (2000), mais que compreender o que os textos querem dizer (o que seria a análise de conteúdo), a "análise de discurso" considera que a linguagem não é transparente, não significa por si só. Para a autora é necessário compreender como as palavras e os discursos significam e/ou significaram em determinados contextos e por qual (quais) sujeito(s) foi ou foram exposto(s).

Acostumamo-nos a entender, em nossa lida cotidiana e automatizada com as palavras, a denominação "método" sem nos debruçarmos devidamente sobre sua contextualização histórico-musical. Na busca por uma melhor compreensão do discurso de Koellreutter com relação ao "método", apresentamos inicialmente uma breve contextualização histórica, já traçada pelo violonista Luis Otavio Santos (2011) e pela flautista Valeria Bittar (2012), sobre a maneira como se dava a formação musical

\footnotetext{
${ }^{4}$ Devido a controvérsias quanto à escrita correta do nome (Émile-Jacques Dalcroze, Émile Jaques-Dalcroze etc), adotei Emile Jaques-Dalcroze (sem acento agudo no Emile, sem a letra c em Jaques e com o hífen entre os nomes Jaques e Dalcroze) conforme pode-se encontrar no site do IJD - Institut Jaques-Dalcroze: $<$ http://www.dalcroze.ch/index.php?option=com_content\&view=article\&id=53\&ltemid=61>
} 
antes dos ideais oitocentistas e como esta foi moldada pela "mentalidade do método conservatorial" (BITTAR, 2012) para contrapor, então, posteriormente, o "método" às propostas de Koellreutter.

\section{Méthode: uma breve contextualização histórica}

De acordo com o violinista brasileiro Luis Otavio de Sousa Santos (2011, p. 5), a forma de ensino musical do período anterior ao século XIX se deu por milhares de anos por meio da antiga tradição de ensino dos artesãos - a relação mestre-aprendiz - como exposto a seguir:

[A] instituição mestre/aprendiz tem sua origem na forma de transmissão do conhecimento entre os artesãos. Esse conhecimento era, na maior parte das vezes, passado oralmente, através da prática iniciática e do ensino privado. No que concerne ao processo de ensino musical, esse sistema concentrava todas as funções pedagógicas na figura do tutor, ou mestre. Cabia ao tutor construir o processo de aprendizado, de acordo com as características intrínsecas de cada discípulo (SANTOS, 2011, p. 5).

Como que ferramentas integradas ao contexto de formação musical mais individualizada, os tratados, diferentemente dos métodos que surgiriam posteriormente, tinham a intenção de registrar o processo de ensino do mestre de maneira não linear e não objetiva, como é esclarecido por Santos:

[os tratados] São os documentos musicais que relatam e descrevem uma práxis específica de um instrumento ou da utilização prática de uma teoria musical, normalmente escritos com caráter autoral e individual. Podem eventualmente se chamar essay ou mesmo méthode, porém o que os define é o descompromisso com uma lógica pedagógica progressiva e autossuficiente. Por isso, eles podem ser ambíguos, repletos de lacunas e com opiniões autorais a respeito de determinados temas. São frutos de um pensamento artesanal, com a intenção de registrar o métier do autor, mas, para atingir a sua completude, sempre dependentes dos segredos implícitos e não revelados pelo mestre (SANTOS, 2011, p. 3).

Reforçando esta visão, a flautista Valeria Bittar (2012, p. 21) completa que esta pedagogia artesanal foi substituída pela instituição do ensino de música padronizado, a partir dos ideais de igualdade e acesso universal ao conhecimento, ditados pela Revolução Francesa, sendo que este longo processo de padronização preconizado pela méthode francesa, será difundido e aperfeiçoado, adentrando o século XIX:

[...] a didática musical começa a transformar-se e esta relação mestre-aprendiz é lentamente substituída por um ensino institucionalizado da música, fixado na figura emblemática do "conservatório", como conhecemos até hoje, cujo modelo foi o Conservatoire de Paris, fundado em $1795 \mathrm{sob}$ as premissas dos novos ideais revolucionários de acesso universal ao ensino e padronização didática por meio do méthode (BITTAR, 2012, p. 30-31).

Deste modo, pode-se dizer que é em torno da época da fundação do Conservatório de Paris em 1795 que surgem os métodos que, contrastando com os tratados, aparecem "carregados de linearidade e previsibilidade" (BITTAR, 2012, p. 33). De acor- 
do com Santos (2011), os métodos diferenciam-se dos tratados em muitos aspectos:

[Os métodos] São os documentos musicais redigidos com o propósito de mostrar todos os estágios de formação musical específica, de uma maneira progressiva, abrangente e clara. Mesmo que não atinjam esse objetivo, eles diferem dos tratados por serem mais diretos na previsão e na solução dos problemas do aprendizado, tornando-se, assim, menos ambíguos ou herméticos. Portanto, esse tipo de documento tem um caráter muito mais didático e funcional do que os tratados. Nesse estudo atribuímos a esse gênero de documento o papel de principal ferramenta utilizada no sistema de ensino coletivo, onde o método sintetiza um curso completo (SANTOS, 2011, p. 4).

Segundo Bittar (2012, p. 128) a mentalidade do "método conservatorial" tem seu modus operandi na padronização do fazer musical através do controle e do "treinamento" técnicos, que partem de um controle disciplinar corpóreo externo ao próprio corpo do sujeito, embasado na emulação de modelos, tanto corpóreos quanto musicais. A autora expõe que esta ideologia de padronização e controle trará como objetivo último a performance musical enquanto "desempenho" e também afirma que esta mentalidade, cunhada nos séculos XVIII e XIX, permeia ainda hoje o fazer musical. Seguem abaixo algumas das características do ensino técnico musical, apontados por Bittar:

[...] A técnica é intensamente detalhada, visando a alta capacitação do performador, como também o melhor e o correto desempenho;

$[\ldots]$

No método musical, a técnica é tecida separadamente de todo o processo criativo; sendo assim, a aquisição da técnica é objetivo e finalidade;

$[\ldots]$

Os caminhos que cada performador trilha para acionar seu corpo no intuito de cumprir esses objetivos são desconhecidos e considerados desinteressantes, por não estarem diretamente conectados com o material textual da música;

O treino é mecanizado e torna-se o centro, o objetivo final do treinador e do treinado;

A performance restringe-se à habilidade em adequação ao treino proposto pelo método, visando desempenho = execução. Busca-se o acerto, evitando-se, a todo custo, o erro e o improviso (motivos para a desqualificação) (BITTAR, 2012, p. $129)^{3}$.

Após esta breve apresentação contextual do surgimento do méthode e de seus desdobramentos dirigidos à performance musical, retomamos o posicionamento de Koellreutter, conforme é apresentado por Teca Alencar de Brito (2001). Para a autora, a participação ativa dos alunos tinha centralidade nas atividades educativas de Koellreutter, de modo que guiava-se:

[...] prioritariamente pela observação e pelo respeito ao universo cultural, aos conhecimentos prévios, às necessidades e aos interesses de seus alunos. A participação ativa, a criação, o debate, a elaboração de hipóteses, a análise crítica, o questionamento... sempre foram princípios básicos presentes em todas as situações de ensino-aprendizagem propostas e/ou coordenadas por ele, posturas derivadas de sua vivência, experiência e reflexão, de suas pesquisas, análises e críticas aos modelos tradicionais de ensino (BRITO, 2001, p. 29).

${ }^{3}$ Bittar (2012) traz ainda outras características além das que foram selecionadas para exposição neste trabalho. 
Através de situações educativas com ênfase na criatividade e na valorização das necessidades dos alunos, Koellreutter propunha a superação do currículo fechado e da padronização, como podemos observar na seguinte declaração de Brito:

\begin{abstract}
Koellreutter sempre propôs a superação do currículo fechado, que determina previamente os conteúdos a serem transmitidos, sem averiguar e avaliar criteriosamente o que realmente é importante ensinar a cada aluno, grupo, em cada contexto ou momento. [...] Desse modo, cabe ao educador facilitar situações para uma aprendizagem autodirigida, com ênfase na criatividade, em lugar da padronização, da planificação e dos currículos rígidos presentes na educação tradicional. Mais do que programas que visam a resultados precisos e imediatos, é preciso contar com princípios metodológicos que favoreçam o relacionamento entre o conhecimento (em suas diversas áreas), a sociedade, o indivíduo, estimulando, e não tolhendo o ser criativo que habita em cada um de nós (BRITO, 2001, p. 31).
\end{abstract}

Observando as características do método conservatorial identificadas por Bittar (2012, p. 129) e relacionando-a com o posicionamento de Koellreutter apresentado por Brito (2001), percebe-se que estes são movimentos de ação e reação, respectivamente.

Retomando e resumindo, grosso modo, as proposições de Bittar, que vê na "aplicação" de um método um desinteresse para com o caminho pessoal do aprendiz através de um treino mecanizado e esvaziado de sentido, o qual irá partir de modelos externos à experiência do aprendiz, na intenção de que sejam atingidas metas impostas por um sistema (mentalidade), onde evita-se "a todo custo o erro e o improviso", sendo o erro e o improviso, "motivos para a desqualificação", construindo-se a técnica sobre a emulação de modelos. Isto abrirá precedentes para que se veja que este processo de formação e de aprendizado subtrai a experiência tanto do aprendiz quanto do professor, situação esta na qual será instalado um sistema de in-formação, um sistema de ensino repositório de dados e conteúdos. Mergulhados nessa mentalidade do método, portanto, o conhecimento será apartado da percepção e da sensibilização do sujeito, o que o distanciará de seu caminho pessoal e processual criativo.

Dito isso, tomamos a liberdade de elencar e ligar os posicionamentos de Bittar com os fundamentos de uma pedagogia musical cujo núcleo é o sujeito, sua experiência e o "saber de experiência" (BONDÍA, 2002), o que enxergamos na proposta de Koellreutter, a qual irá defender a valorização das necessidades e dos interesses dos alunos proporcionando atividades com ênfase na criatividade. Na contramão dos ideais de "correto desempenho", da "mais perfeita emulação do modelo externo" (BITTAR, 2012, p. 129), Koellreutter propõe "uma aprendizagem autodirigida [...] em lugar da padronização" (BRITO, 2001, p. 31).

Identificamos, portanto, que a crítica de Koellreutter pode se referir à mentalidade oitocentista e aos moldes do método conservatorial (BITTAR, 2012). Apesar de Hans-Joachim Koellreutter se reportar à realidade encontrada por ele em pleno final do século XX, conforme afirma Bittar (2002, p. 34), a formação musical atual ainda se dá dentro dos princípios do método do Conservatoire.

Desta forma, compreendemos o "não-método" de Koellreutter não como uma recusa a todas as ricas ideias, abordagens e propostas já elaboradas pelas pedagogias 
musicais, mas sim como uma postura tomada por aquele professor que não pretende ser um mero aplicador de métodos, um professor-buscador da ativação da percepção e da sensibilização de cada aluno. Entendemos que seu posicionamento se contrapõe, em parte, aos "métodos ativos", quando estes são compreendidos e "aplicados" de maneira pré-definida e engessada, distante de transformações. Dalcroze tinha, por exemplo, a superação do ensino musical já convencionado no final do século XIX enquanto ideal e entendia que sua proposta deveria ser constantemente atualizada pelos educadores conforme as realidades educacionais encontradas. Desse modo, podemos entender que as posições de Dalcroze possibilitaram uma visão do professor para cada pessoa-aluno, para cada uma das suas experiências sensíveis, o que torna "seu método" num processo didático também em constante transformação.

Entendemos assim que a crítica de Koellreutter, portanto, se refere ao uso de abordagens de educação musical de modo restrito, fechadas em si mesmas, onde não é levada em consideração a experiência percepto-sensível de cada sujeito-aluno. Vemos que Koellreutter expõe a perspectiva de que o professor necessita constantemente desenvolver o pensamento crítico e a sua própria autonomia perceptiva para, primeiramente, conhecer o seu aluno, seu grupo de alunos e identificar suas próprias possibilidades de contribuição para com a formação do aluno/aprendiz, levando em consideração condições sociais, desejos, facilidades e limitações corpóreas e intelectuais de cada um. Conforme afirma Brito (2001):

O professor [Koellreutter] sempre defendeu como fator principal a necessidade da presença do "espírito criador", princípio vital ao ambiente necessário ao ensino artístico. Presos a métodos e modelos programados, educadores acabam por minar o espírito criativo, vivo e curioso que habita nos alunos (BRITO, 2001, p. $30)$.

Sob essa ótica, entendemos que o professor de música necessita traçar um caminho em direção ao conhecimento e à experiência das mais diversas formas existentes de se trabalhar com a educação musical e ainda estar aberto e atualizado para a ampliação e criação constantes de seus próprios modos de ensinar, o que mostra um caminho inicial e constante em direção a uma "escuta de si", "um cuidado de si" (FOUCAULT, 2006, p. 3-34), que estaria acima do moderno "conhecimento de si".

Em nosso entender, o desconhecimento quanto à história da educação musical e aos "métodos ativos" de educação musical podem contribuir para o fechamento, para a limitação e para a imposição, muito mais do que as estruturas rígidas de alguns métodos, pois consideramos que para "abrir, transcender, transgredir, ir além", enfim, para superar o "método", é preciso conhecê-lo.

Consideramos que Koellreutter e Dalcroze têm, ambos, propostas reativas aos ideais oitocentistas do método conservatorial. Neste sentido, identificamos que há, inclusive, grande proximidade entre aspectos centrais dos posicionamentos dos dois autores, dando destaque aqui à superação dos modelos convencionais, canônicos de ensino por caminho percepto-sensível que valoriza a experiência musical de cada um. 


\section{Dalcroze: reação ao "método"}

Conforme afirma Madureira (2008), Emile Jaques-Dalcroze (1865 - 1950), educador musical suiço, questionava a metodologia convencional de música justamente por observar a dificuldade que seus alunos de harmonia teórica e solfejo tinham em associar os conteúdos teóricos com a prática musical. Teoria e prática eram âmbitos totalmente desvinculados neste processo de ensino dominado por uma racionalidade abstrata.

Para Dalcroze, sobretudo, o aluno deve receber primeiramente uma considerável educação musical fundamentada no desenvolvimento da sensibilidade e das faculdades auditivas para depois ser iniciado no conhecimento da teoria musical (MADUREIRA, 2008). A esse respeito, Jaques-Dalcroze afirma: "O objetivo do meu ensino é permitir que os meus alunos digam, ao final de seus estudos, não apenas 'eu sei', mas 'eu sinto', e depois, cultivar neles um desejo de autoexpressão" (JAQUES-DALCROZE, 1917, p. viii apud MADUREIRA, 2008, p. 70).

Dando prosseguimento a esse posicionamento que prioriza a sensibilização de cada um, citamos a prática de Dalcroze (1948), que nos mostra uma inversão de direção frente ao método convencional de didática musical, ainda vigente nos dias de hoje:

O ensino tradicional da música geralmente começa pelo estudo dos sinais que servem para anotar as melodias, os ritmos, os valores e os acordes. Não seria mais lógico fazer o contrário, ou seja, estudar a notação somente no momento em que o ouvido tenha aprendido a apreciar as relações entre as sonoridades, suas associações, valores e nuances? Não seria estranho ensinar a criança a escrever antes que ela saiba falar? (JAQUES-DALCROZE, 1948, p. 170 apud MADUREIRA, 2008, p. 69).

Dalcroze tinha consciência da abstração e racionalização excessivas contidas no ensino tradicional ao qual foi submetido na escola, como podemos observar em sua declaração que segue:

\footnotetext{
A maior parte dos professores do colégio, desde a tenra idade, impunha-nos deveres sem nos explicar o seu sentido e eles não faziam - salvo raras exceções qualquer esforço para nos conhecer, motivar ou ajudar (JAQUES-DALCROZE, 1948, p. 195 apud MADUREIRA, 2008, p. 33).
}

Em contraposição às experiências de iniciação musical por meio de métodos que teve na infância, desde as aulas de piano aos seis anos de idade até as aulas de música que teve no colégio, que visavam um desempenho meramente técnico e virtuosístico, Dalcroze buscou elaborar exercícios que tivessem o caráter de jogo e que garantissem aos alunos que as lições de música "fossem uma alegria, não mais uma tortura" (JAQUES-DALCROZE, 1907, p. 44 apud MADUREIRA, 2008, p. 34).

Jaques-Dalcroze deixou grande quantidade de escritos nos quais se encontram o seu pensamento estético-pedagógico em relação à música, à dança e à dramaturgia, bem como composições para serem usadas na sua própria prática pedagógica e alguns cadernos didáticos. Entretanto, segundo Mariani (2011, p. 40), em todo seu le- 
gado musical-pedagógico, não há um método sistematizado e escrito. Sendo assim, seus alunos rythmiciens ${ }^{4}$, a partir da experiência vivida nas aulas de Rítmica junto a Dalcroze, "passaram a elaborar exercícios de acordo com a realidade de seus alunos e a especificidade artística de cada grupo. Muitos desses exercícios e experiências foram relatados na revista Le Rythme, que teve grande circulação na Europa no início do século XX" (MARIANI, 2011, p. 40). Segundo a autora, era desejo de Dalcroze que, uma vez vivenciados, experienciados e compreendidos os princípios, a "Rítmica" pudesse ser constantemente renovada pelos professores, adaptando-se às experiências sociais e culturais dos alunos.

Deste modo, refletiremos sobre o uso do termo "Método Dalcroze" para se referir à "Rítmica", considerando que a proposta de Jaques-Dalcroze se difere em muito da mentalidade de la méthode e observando a ideia central da "Rítmica" como "negação de um modelo pré-estabelecido" e como "experiência pessoal" de cada um (MADUREIRA, 2008, p. 36).

\section{"Método dalcroze" ou "rítmica"?}

Nas obras consultadas, percebe-se que são usados diferentes termos para se referir à proposta de Dalcroze: "Método Dalcroze" (MARIANI, 2011, p. 27); "sistema de educação musical denominado Rítmica (Rythmique)" e "Ginástica Rítmica ou simplesmente Rítmica (Rythmique)" (MADUREIRA, 2008, p. XII e p. 3); “Pedagogia Dalcroze", "Rítmica" e "Rítmica Dalcroze" (MANTOVANI, 2009, p. 15, p. 18 e p. 41); "método chamado 'eurritmia'"5 (SUQUET, 2009, p. 515), “Dalcroze Eurhythmics" são alguns exemplos.

Segundo Madureira, Dalcroze se referia a seu sistema de educação musical como "Ginástica Rítmica". Porém, "para evitar confusões com outros sistemas de ginástica fundamentados no ritmo, Dalcroze passou a denominar o seu método simplesmente de Rítmica (La Rythmique)" (MADUREIRA, 2008, p. 73).

No entanto, mesmo não usando o termo "Método Dalcroze", o próprio JaquesDalcroze refere-se indiscriminadamente à Rítmica como "meu método" (MADUREIRA, 2008). Compreendemos que é justamente por estar inserido num movimento de transição que Dalcroze não irá questionar o uso da palavra "método"6, visto que as discussões a respeito da "mentalidade do método conservatorial", por exemplo, são recentes (SANTOS, 2011; BITTAR, 2012).

No site do IJD - Institut Jaques-Dalcroze pode-se encontrar frequentemente a utilização da expressão "la méthode Jaques-Dalcroze"7, apesar de que não há uma

\footnotetext{
4 "Rythmicien é uma palavra francesa que indica o profissional ou o estudante do sistema de Jaques-Dalcroze conhecido como Rítmica (Rythmique)" (MADUREIRA, 2008, p. 13)

${ }^{5}$ Neste caso, conforme afirma Madureira (2008, p. 3), a "Rítmica", a proposta de educação musical de Dalcroze, é confundida com a "Euritmia", uma técnica de movimento corporal que nasceu como uma das muitas ferramentas pedagógicas da Antroposofia e da Educação nas Escolas Waldorf construída por Rudolf Steiner. Conforme pude confirmar pessoalmente com o professor Iramar Rodrigues na oficina "A Rítmica Dalcroze" em Caxias do Sul/RS, esta confusão se deve a uma tradução errônea de Rythmique (do francês) para Eurhythmics (em inglês).

${ }^{6} \mathrm{O}$ uso do termo "método" está também atualmente relacionado à necessidade encontrada pelos criadores e difusores de algumas propostas de educação de registrar as suas marcas (trademarks) de forma que estas tenham grande impacto comercial no "mercado da educação". A palavra Method, neste caso, dá força às patentes de marcas, uma vez que faz referência a algo que está bem estruturado e que tem comprovada eficácia. Seguem alguns exemplos de utilização do termo método por algumas propostas de "métodos alternativos" de educação e conscientização corporais na trademark: "DeRose Method", "The Feldenkrais Method of Somatic Education", "Rolf Method Body Work", "Método GDS" - aqui, no caso, todos métodos de educação somática.

${ }^{7}$ Disponível em: <http://www.dalcroze.ch/index.php?option=com_content\&view=article\&id=53\&ltemid=61>. Acesso em: 27 ago. 2014.
} 
trademark, não há um símbolo que represente a proposta. Provavelmente, o fato de não haver uma marca registrada atualmente para a Rítmica deve contribuir para esta confusão quanto ao termo a ser utilizado para se referir à proposta de Dalcroze.

$\mathrm{Na}$ ocasião de um encontro ${ }^{8}$ com o professor Iramar Rodrigues", na oficina "A Rítmica Dalcroze" por ele ministrada, foi questionado se a Rítmica era um método, ao que o professor afirmou que Jaques-Dalcroze chamava sua proposta de método, mas que atualmente não se compreende desta forma. Segundo o professor Iramar, a proposta "não é um método, é uma pedagogia, uma maneira de se transmitir algo, seria uma metodologia" (RODRIGUES, 2014).

Madureira (2008), em sua tese de doutorado, um primeiro trabalho de tradução dos pensamentos de Jaques-Dalcroze para o português, não utiliza o termo "Método Dalcroze", por exemplo, realidade também encontrada em Fonterrada (2005). Estes dois autores tratam o sistema de educação musical proposto por Jaques-Dalcroze pelo nome dado pelo seu criador: "Rítmica", tradução para o português de La Rythmique.

Como mencionado, esta é uma questão de léxico e que percebemos poder gerar possíveis problemas de discurso que, por sua vez, acarretam uma série de desentendidos, como, por exemplo, as posturas postas por Koellreutter e por Jaques-Dalcroze com relação às suas propostas e com relação ao "método". Para Orlandi (2000, p. 38), "todo dizer é ideologicamente marcado. É na língua que a ideologia se materializa. Nas palavras dos sujeitos". Para a mesma autora (2000, p. 39), do ponto de vista da relação de forças, as palavras ditas significam de formas diferentes dependendo do lugar que o sujeito que as profere ocupa.

Dessa maneira, a questão seria de que forma a palavra "método" significou diferentemente para Koellreutter e para Dalcroze. Cabe ser levantado que o primeiro foi um ícone importante para o trabalho da música de vanguarda brasileira, ao apresentar enfaticamente bases de uma música que rompe com o sistema tonal/formal ocidental. Neste caso, a palavra "método" já está incluída no mesmo "pacote" de significados das ideias e do ambiente tonal que precisavam ser superadas da música tradicional europeia, significando, de antemão, um conceito que remete a algo "ultrapassado". Já Dalcroze está inserido historicamente no início do século XX, o que o coloca numa relação diferente com as transformações que a música ocidental estava enfrentando e com os significados e repercussões contrárias à sua postura que a palavra "método" poderia desempenhar futuramente.

\section{Considerações finais}

Compreendemos que não ter método é "ter" todos os métodos, é conhecê-los de modo a estar instrumentalizado com suas técnicas e estratégias sobretudo pedagógicas. Dessa forma, é possível compreender o "não ter método" de Koellreutter se

\footnotetext{
${ }^{8}$ Este encontro ocorreu entre o professor Iramar Rodrigues e Rafael Prim Meurer, um dos autores deste texto, em um dos intervalos da oficina "A Rítmica Dalcroze" ocorrida em Caxias do Sul/RS de 16 à 19 de Outubro de 2014.

9 "Iramar Rodrigues graduou-se em piano pela Universidade Federal de Uberlândia, foi professor na Escola de Música da Universidade Federal de Goiás e, algum tempo depois, conquistou na Suiça o certificado de rythmicien. Há mais de 30 anos Iramar Rodrigues se ocupa da formação musical de crianças, jovens e profissionais nas mesmas salas ocupadas por Dalcroze no Instituto Jaques-Dalcroze de Genebra, situado na rua Terrassière, número 44, inaugurado em 1915." (MADUREIRA, 2008, p. 5).
} 
esta disposição pressupor a superação das limitações existentes nos métodos, sendo necessário, assim, conhecê-los. No entanto, pensamos que o discurso de Koellreutter de reação ao método pode contribuir, quando visto superficialmente, como validação para um abandono dos "métodos ativos" no Brasil, que podem, então, ser vistos como propostas ultrapassadas, que já não servem mais. Fonterrada (2005) aponta para a existência de um certo esvaziamento de ações e práticas pedagógicas, técnicas, que poderiam munir os professores de música, como se pudessem ser um "ponto de partida", provendo o professor, por meio da experiência com a música propriamente, de escolhas que o fizesse aproximar de cada aluno e de cada grupo de alunos, classes, com suas necessidades particulares.

Fonterrada (2005, p. 107-108) afirma que parte dos "métodos ativos" chegaram a ser introduzidos no Brasil nas décadas de 1950 e 1960 em alguns grandes centros e escolas de música, mas que, "por uma série de circunstâncias, entre as quais a exclusão da disciplina Música dos currículos escolares, substituída pela Educação Artística desde 1971 (LDB n.5692/71), muitas dessas abordagens ficaram esquecidas [...]". Acerca deste esvaziamento, Fonterrada (2005) afirma:

O esquecimento dos métodos ativos de educação musical vem sendo danoso ao ensino de música no país, provocando duas posturas opostas: a de adotar um dos métodos acriticamente e de maneira descontextualizada, descartando outras possibilidades, e a de ignorar seus procedimentos, investindo em propostas pessoais, geralmente baseadas em ensaio-e-erro e, em geral, privilegiando o ensino técnico instrumental (leia-se treinamento dos olhos e das mãos) ou a diversão, dentro do pressuposto de que música é lazer ${ }^{11}$ (FONTERRADA, 2005, p. 108).

Vejo que se partíssemos no período de nossa formação para futuro músico-professor, em direção a uma proximidade e um aprofundamento para com a prática ativa destas pedagogias as quais iniciaram seus caminhos no início do século XX e, por serem em seu fundamento, baseadas no "fazer musical" (o que, em si, já lhes delega uma boa carga de flexibilidade e possibilidades de transformações pessoais), na percepção e na sensibilização única e de cada um, poderíamos, aí sim, escolher um destes caminhos como início de um fundamento particular, próprio.

Se o professor de música não deve ser um aplicador de métodos, isto não significa, em absoluto, que ele não os deva conhecer. Entendemos que não existam "receitas prontas" que resolvam todos os problemas, mas é inegável a importância do conhecimento e, sobretudo, da vivência e da experiência com estas muitas pedagogias e propostas pedagógicas, indo ao encontro à afirmação do professor Sérgio Figueiredo:

\footnotetext{
${ }^{10} \mathrm{O}$ conceito de arte e música como lazer e entretenimento tem sua origem na mentalidade construída pela "indústria cultural", termo desenvolvido por Max Horkheimer e Theodor Adorno e no seu prolongamento atual, o qual denomina-se "indústria do entretenimento". Este conceito reduz a experiência em arte ao entretenimento e ao lazer. Percebo que há uma prática e um discurso mais ou menos aceitos que caminham na direção de trazer músicas presentes na grande mídia impostas pela "indústria do entretenimento" para as aulas de música, sob o pretexto de caminhar ao encontro da realidade musical do aluno. Vejo inclusive que esta pode ser uma interpretação possível da concepção de Koellreutter de que devemos ensinar "aquilo que o aluno quer saber" (BRITO, 2001, p. 31), apesar de, eu mesmo, não a entender assim. Considero esta uma posição extremamente comodista, pois há um esquecimento de que a memória musical possa vir a ser um discurso condicionado culturalmente. A música veiculada e imposta pela mídia já tem significado muito forte na vida da maioria das pessoas e, a partir daí, entendo a escola como sendo um espaço onde se apontam outras possibilidades, onde se propiciam experiências outras, para que os alunos possam vir a ter outras perspectivas, ganhem mais autonomia, confrontem-se com o outro e com as diferenças.
} 
[...] Cada um desses métodos tem a sua coerência interna. Eu posso não concordar, mas há uma coerência. Há uma tentativa de tratar o fenômeno musical de maneira organizada. Essa é uma questão importante não apenas para os métodos tradicionais, mas para qualquer estudo, qualquer matéria a ser levada para a escola. Temos de estudar mais profundamente e entender os métodos. Vamos enxergar mais coisas novas do que estamos acostumados (FIGUEIREDO, 2012, p. 92).

Em conformidade com Fonterrada, destacamos a importância de que os educadores musicais pioneiros sejam revisitados para se fortalecer a área da educação musical no Brasil, "não para serem adotados tal como se apresentam em suas propostas de origem, mas como fonte vital, da qual se podem extrair subsídios para propostas educacionais adequadas à escola e à cultura brasileiras" (FONTERRADA, 2005, p. 108).

Ao contrário da possível interpretação de que haveria um antagonismo entre as proposições de Koellreutter e Jaques-Dalcroze, percebemos que ambos defenderam uma ação pedagógica musical que nascesse da prática e da percepção, do fazer musical, para que, posteriormente, se pudesse analisar e intelectualizar os conteúdos musicais. Desta forma, consideramos vários elementos da "Rítmica Dalcroze" como possibilidades de abordagem prática para muitos dos posicionamentos de Koellreutter de reação ao "método", de expansão da consciência, mudança do ser humano e valorização das experiências dos alunos. Apesar de que Koellreutter, não diretamente, abordasse o corpo como centro de seus posicionamentos sobre a formação do músico, a sua postura perante a música, de maneira geral, pôde nos encaminhar para a construção de um conceito onde educação e formação musical caminham de mãos dadas com a percepção e a sensibilização do corpo. Uma possibilidade de se pensar a pedagogia musical como uma proposta, sobretudo, somática.

Com este trabalho não pretendemos absolutamente determinar os entendimentos acerca da temática, mas apenas "jogar uma pedra no lago" de modo a causar o movimento, tomando de empréstimo a fala de Koellreutter:

O mundo intelectual, cultural é um grande lago, onde todos nós jogamos pedras. Umas um pouco maiores, outras menores, mas nós movimentamos esse lago. Isto é o que me parece essencial: o movimento (KOELLREUTTER, 1997, p. 135 apud BRITO, 2001, p. 51).

Vemos que esta é uma discussão necessária e pertinente a ser feita por aqueles professores de música em formação que não pretendem ser meros aplicadores de métodos, considerando necessária a "ampliação da consciência", como diria Koellreutter, com relação às ideologias de educação musical com as quais nos identificamos e das possíveis repercussões práticas dos nossos discursos.

\section{Referências}

BITTAR, Valeria Maria Fuser. Músico e Ato. Tese de Doutorado em Artes Cênicas. Campinas: Universidade Estadual de Campinas, 2012.

BONDÍA, Jorge Larrosa. Notas sobre a experiência e o saber de experiência. Tradução 
de João Wanderley Geraldi. Revista Brasileira de Educação, n. 19, Campinas, 2002.

BRITO, Teca Alencar de. Koellreutter educador: O humano como objetivo da educação musical. São Paulo: Peirópolis, 2001.

FIGUEIREDO, Sérgio Luiz Ferreira de. Roda de conversa 3. In: A Música na Escola. São Paulo: Allucci \& Associados Comunicações, p. 90-95, 2012.

FONTERRADA, Marisa Trench de Oliveira. De Tramas e Fios: um ensaio sobre música e educação. São Paulo: UNESP, 2005.

FOUCAULT, Michel. A Hermenêutica do Sujeito. Tradução de Márcio Alves da Fonseca e Salma Tannus Muchail. São Paulo: Martins Fontes, 2006.

IJD - Institut Jaques-Dalcroze. Disponível em:

$<$ http://www.dalcroze.ch/index.php?option=com_content\&view=article\&id=53\&ltemid $=61>$.

Acesso em: 27 ago. 2014.

MADUREIRA, José Rafael. Émile Jaques-Dalcroze: sobre a experiência poética da rítmica: uma exposição em 9 quadros inacabados. Tese de Doutorado em Educação. Campinas: Universidade Estadual de Campinas, 2008.

MANTOVANI, Michelle. O movimento corporal na educação musical: Influências de Émile Jaques-Dalcroze. Dissertação de Mestrado em Música. São Paulo: Universidade Estadual Paulista, 2009.

MARIANI, Silvana. Émile Jaques-Dalcroze: A música e o movimento. In: MATEIRO, Teresa; ILARI, Beatriz (Org.). Pedagogias em Educação Musical. Curitiba: Ibpex, 2011. p. 25-54.

MEURER, Rafael Prim. Koellreutter e Dalcroze: reflexões sobre questões do 'método' a partir de uma experiência de estágio. TCC (Graduação) - Universidade do Estado de Santa Catarina, Centro de Artes, Licenciatura em Música, Florianópolis, 2014.

ORLANDI, Eni P. Análise de discurso: princípios e procedimentos. Campinas: Pontes, 2000.

RODRIGUES, Iramar. A Rítmica Dalcroze: uma educação por e para a música. Oficina realizada em Ponto de Cultura Casa das Etnias, Caxias do Sul/RS de 16 à 19 de Outubro de 2014. $20 \mathrm{~h}$

SANTOS, Luis Otavio. "A Chave do Artesão" um olhar sobre o paradoxo da relação mestre/aprendiz e o ensino metodizado do violino barroco. (Tese Doutoramento em Práticas Interpretativas), Instituto de Artes, Programa de Pós-Graduação em Música, Universidade Estadual de Campinas, Campinas, 2011. 